\title{
"It Was Like A Lightning Bolt Hitting My World": \\ Feeling Shattered in a First Crisis in Psychosis
}

\author{
Sarah Bögle ${ }^{a}$ \& Zoë Boden ${ }^{b}$
}

${ }^{a}$ Division of Psychology, School of Applied Science, London South Bank University, London, UK

${ }^{\mathrm{b}}$ School of Applied Social Science, University of Brighton, Brighton, UK

Accepted for publication in Qualitative Research in Psychology (3rd June 2019).

\section{Corresponding Author:}

Sarah Bögle

Division of Psychology - School of Applied Sciences

London South Bank University

103 Borough Road

London SE1 OAA

United Kingdom

Email: bogles4@lsbu.ac.uk

Tel: 00447724562430 
Background: The felt and emotional aspects of psychosis are poorly understood, however, their importance for the aetiology of, and recovery from, psychosis is increasingly accepted. Individuals experiencing psychosis often come into contact with mental health services during a crisis. Currently little is known about the emotional and felt aspects of this experience, yet this could support clinical intervention at this time.

Aims: This research aims to gain an in-depth understanding of the lived, felt experiences of a first crisis in psychosis.

Method: The study took a hermeneutic phenomenological perspective and utilised visual methods. Seven participants participated in idiographic, multi-modal interviews about their experiences.

Results: Participants described their first crisis in psychosis as a shattering experience, entwined with their experiences of interpersonal trauma. In crisis, participants lost basic trust in the world; felt enveloped in a strange, threatening atmosphere, and lacked a sense of belonging.

Conclusions: Attention to the felt aspects of a crisis indicate the existential, intersubjective and traumatic nature of the experience. Psychosocial, family and trauma-focused approaches that take into account the holistic, embodied and contextual nature of psychosis experiences seem best-placed to support treatment and research in this area.

Declaration of Interest: None.

Keywords: UK; mental health; early psychosis; feelings; embodiment; interpretative phenomenological analysis 
Psychosis is characterised by unusual perceptual experiences, including hearing voices, having visions, or holding unusual beliefs. Previous research found that 5 to $8 \%$ of the general population have had psychotic-like experiences (PLE), with $8 \%$ of that group going on to develop psychosis within two years (Hanssen et al. 2005; Van Os et al. 2009). Experiences of unusual perceptual phenomena, including a first episode of psychosis, are not always experienced as distressing (Yung et al., 2006), and a person may not enter services until a crisis point is reached (Malla et al. 2006). 'Crisis' refers to an acute state of heightened distress or risk (perhaps leading to an inpatient admission), but service-user and clinician perspectives on what constitutes a crisis can diverge, and service-users have reported feeling that they are often not treated humanely at this time (Mind 2011). Treatment and support in crisis and during the first three years after an initial episode of psychosis are deemed 'critical' with regards to long-term trajectory (Birchwood et al., 2013; Dunkley, Bates \& Findlay 2015). Guidance from the National Institute of Health and Care Excellence (NICE, 2014) on managing psychosis and schizophrenia in adults states that Early Intervention in Psychosis (EI) services should be accessible to all people with a first episode of psychosis, and offer oral antipsychotic medication in conjunction with cognitivebehavioural therapy and family intervention. However, it has been increasingly advocated that a wider range of treatment choices, including emotion-focused approaches (Livingstone, Harper \& Gillanders 2009), may improve the ability of El services to engage service-users and promote recovery (Morrison \& Shiers 2014).

The predominant biomedical model of mental distress conceptualises psychosis as a severe, chronic brain disorder rooted in biological disturbances and neurological deficits (Freeman \& Garety 2003; National Institute of Mental Health 2016). However, more recently it has been acknowledged that there may be social and psychological routes to psychosis (Read \& Dillon 
2013; Murray 2016; Preti \& Cella 2010). Emotional experience is also implicated in the aetiology of psychosis (Birchwood 2003; Garety et al. 2001), although there remains disagreement about the mechanisms through which emotions, or more broadly, felt experiences, might contribute to its development and maintenance (Bentall et al. 2001; Freeman 2007; Rhodes \& Jakes 2009). Over the past two decades and with the support of the service-user/survivor movement (e.g. Romme et al. 2009), social, emotional and psychological recovery has also been recognised as important (NICE 2014; The British Psychological Society 2014). New models of recovery have been developed (Ellison et al. 2016; Slade \& Longden 2015), which define recovery as an individual and meaningful journey or process, and take into account the complexities and many, subjective meanings of recovery (Davidson 2016; Jacob 2015). A survivor discourse has emerged and has begun to challenge the 'psychopathology' of breakdown and crisis (Wallcraft \& Michaelson 2013, p.177). First-person accounts of psychosis as well as phenomenologically-oriented and survivor research (e.g. Attard et al. 2017; Boden, Larkin \& Iyer 2019; Deegan 1996, 2008; Dunkley et al. 2015; Hickman et al. 2015; Luderowski \& Boden 2019; Sin, Moone \& Wellman 2005) continue to support this shift towards recovery-oriented and person-centred practice and research in the field (Amering 2009), which is echoed in a renewed acknowledgment of the importance of emotional experience after a period of neglect, where symptom-oriented pharmacological and cognitive-behavioural approaches to treatment were favoured (Gumley et al. 2013; Carr et al. 2017). A number of autoethnographical and biographical accounts of psychosis including 'Peer-Professional First-Person Account: Schizophrenia From the Inside' by Peter Chadwick (2007), 'The Tale of an Ordinary Little Girl' by Jacqui Dillon (2010), 'An Existential Case Study of Madness' by Scott Kiser (2004), 'The Long Road Back' by Kathleen Lynch (2000), and Living with Voices - 50 Stories of Recovery edited by Romme et al. (2009) 
document how 'objective' clinical descriptions of psychosis are often imposed on people's actual lived experiences but fail to adequately describe these experiences and do not achieve real understanding (Chadwick 2007; Kiser 2004). More qualitative, phenomenologically-oriented research, which honours the idiographic (Smith, Flowers \& Larkin, 2009) and contextualises it within the participant's particular lifeworld (Husserl 1970) is needed in order to get closer to the fullness and richness of what it feels like to find oneself in a first crisis in psychosis. According to phenomenologists, the only way of exploring human experience in the context of the individual's lifeworld is via understanding a phenomenon as it appears to the individual in consciousness (Dilthey 2002; Langdridge 2007). This involves in-depth description, interpretation and reflection upon subjective experience (Heidegger 1962). Through adopting an open-minded empathic attitude - and 'bracketing' what is already known about the phenomenon and the process of 'dwelling' with the data in phenomenological research (Smith et al. 2009) - the phenomenon under investigation is given space to emerge and reveal itself, weaving itself into our understanding and challenging taken-for-granted knowledge and assumptions (Finlay 2014). Hermeneutic-phenomenological research has successfully created new understandings and in-depth knowledge - especially within contemporary healthcare research - (Brocki \& Wearden, 2006; Peat, Rodriguez \& Smith 2019; Rodriguez \& Smith, 2018; Smith \& Osborn, 2015a), through the collection of idiographic, rich and nuanced data (Smith et al. 2009). Studies have shown that phenomenological research is particularly useful when researching ambiguous, contradictory, pre-reflective and emotional experiences (Boden \& Eatough 2014; Smith \& Osborn 2008). Adopting a hermeneutic-phenomenological approach is therefore considered most suitable in order to explore and understand, as fully as possible, the multilayered, subjective and embodied nature of a first psychotic crisis. 
Felt experiences have often been regarded as irrelevant epiphenomena (Fuchs, 2013), as psychotic experiences are commonly conceptualised as symptoms of schizophrenia spectrum disorders, and accordingly associated with the diminished capacity to feel, often referred to as 'flat affect' (American Psychiatric Association 2013; NICE 2014; Moncrieff 2013). However, more recent research characterises psychosis as a severe and disruptive personal crisis involving intense feelings of shame, threat, anxiety, confusion, anger and despair (Birchwood et al. 2002; Dunkley et al. 2015; Freeman 2007; Hutchins, Rhodes, \& Keville 2016; Schwannauer 2013). Garety et al. (2001) suggest that these feelings occur in direct response to experiences of unusual perceptual experiences and in response to adverse life events and trauma, which have been associated with the onset of psychosis (Gumley et al. 2013; Read et al. 2005).

While the role of feelings in the formation and maintenance of psychosis has been welldocumented in recent years, few studies have investigated felt experiences which occur in response to psychotic experiences and influence the individual's adaption to and recovery from psychosis. Some research has associated a first episode of psychosis with posttraumatic stress disorder (PTSD); however, the relationship between psychosis and PTSD seems complex and remains largely unclear (Brunet et al. 2012; Dunkley, et al. 2015; Morrison, Frame, \& Larkin, 2003). Further, it has been shown that psychosis increases the risk of suicidality, predominantly in the first year after a first episode of psychosis (Dutta et al. 2010), due to increased feelings of hopelessness, self-devaluation, demoralisation and depression (Melle \& Barrett 2012; Pompili et al., 2008; Robinson et al. 2010; Tarrier et al. 2007). Valuable insights on feeling in psychosis have been provided by early phenomenological research; however, with a particular focus on delusions beliefs and prodromal phase of psychosis. R.D Laing (2010) described the existential-phenomenological 
basis of psychosis as a sense of unreality in the world, emerging from harmful social relations. Jaspers (1963) presumed the formation of 'delusional beliefs' to be preceded by the 'delusional mood', which he described as a feeling of uncanniness and anxious anticipation: "that there is something suspicious afoot [...] Something seems in the air which the patient cannot account for, a distrustful, uncomfortable, uncanny tension invades him" (Jaspers 1963, p.98). Jaspers claimed that a feeling of unreality is central to the 'delusional mood', an all-pervasive strangeness, where things appear 'somehow' different and not quite 'real' (Ratcliffe 2013, p.5). Building on Jasper's work, Conrad (1958) developed a 'stage model' of for the development of 'delusional beliefs' and described the initial stage preceding psychosis as trema (Greek: stage fright), the experience of something indefinable being in the air (Mishara 2009). Trema is further characterised by feelings of anxiety, suspiciousness and detachment form others (Mishara 2009; Sass \& Pienkos 2013).

Conrad's stage model becomes especially relevant with regards to Jaspers' (1963) second hypothesis, the disturbance of the core self at the heart of psychosis. Jaspers considers disturbances in the most primitive, pre-reflective sense of self, the minimal self, also referred to as core self or ipseity to underlie and generate psychotic experiences (Nelson, Parnas \& Sass 2014). Illuminating Jaspers' ipseity disturbance, Conrad (1958) proposes the possibility of an internal apophany, involving different forms of altered self-experience, such as a diminished sense of existence, depersonalisation and distorted self-other boundaries (Nelson et al. 2014). More recent phenomenological research confirms Jaspers' (1963) notion of disturbed self-experience in psychosis (Henriksen \& Parnas 2012; Parnas \& Handest 2003), giving rise to the ipseity-disturbance model (IDM) proposed by Sass and Parnas (2003). According to the IDM, ipseity disturbance in psychosis consists of hyperreflexivity; the emergence of ordinarily tacit experience into awareness, and diminished self- 
affection, a weakened sense of existing, ranging from somatic estrangement to feelings of non-existence (Nelson et al. 2014; Parnas et al. 2005). However, the self-disorder approach neglects the fact that the human self is fundamentally relational (Andersen \& Chen 2002). The individual is always embedded in a wider, social context, thus even the most basic sense of self is developmentally and constitutively dependent on interpersonal relations (Ratcliffe 2017; Reddy 2001; Zeedyk 2006).

Contemporary therapeutic approaches argue that unbearable emotional experiences are at the core of psychosis experiences, and that "expanding and strengthening the patient's emotional subjective life becomes the primary goal of treatment" (Garfield, Simon \& Ramachandran 2013, p. 37). Interventions such as Open Dialogue emphasise emotionregulation as part of their work with clients and their social networks (Seikkula et al. 2003; 2006). Despite this, there has been very little empirical exploration of the emotional aspects of psychosis experiences, and even less from the individual's perspective (Hutchins et al., 2016). However, a number of recent qualitative studies have indirectly implicated the importance of felt experiences in understanding and managing psychotic experiences. Episodes of voice hearing were associated with feelings of intense fear, guilt and blame towards close others or the self - in a study which investigated the benefits of group personbased cognitive therapy for voice hearers (Goodliffe et al. 2010). Rhodes and Jakes (2004) found that participants used metaphors and metonymies congruent with and reflective of their emotions in the pre-delusional period and during a psychotic episode in an attempt to make sense of unusual phenomenal experiences. Attard et al. (2017) explored the meaning of recovering from a first episode of psychosis and found that participants' path of adaption involved confusion, loneliness, shock and loss of trust, but also positive changes and posttraumatic growth in some cases. Another important exception is a recent study exploring 
individuals' emotional experience of 'delusions', which found that participants report a range of different feelings before, during and after a psychotic breakdown (Hutchins et al. 2016). Building on this paper and re-emerging phenomenologically-oriented qualitative literature on feelings in psychosis, this study specifically explores individuals felt experiences within the context of a first crisis in psychosis - drawing on Fuchs' (2013) phenomenology of affectivity (including vital and existential feelings, affective atmospheres, mood and emotions) - to understand the role of felt experiences in the adaption to and recovery from psychosis, and to further explore the potential traumatic effects of a first crisis that emerging evidence has highlighted (Dunkley et al. 2015).

\section{The Approach}

A hermeneutic-phenomenological, multimodal qualitative research approach was used to explore participants' felt experiences in a first crisis in psychosis within the individual's social context and from their idiographic perspective (Gelling 2015; Pathak, Jena \& Kalra 2013; Willig, 2013). Hermeneutic-phenomenological research aims to explore the 'what is' (noema) and 'how it is experienced and understood' (noesis; Husserl 1962), while embracing the intersubjective, embodied and embedded nature of human experience (Boden \& Eatough, 2014; Churchill 2018, Langdridge 2007). Hermeneutic phenomenologists explicitly use interpretation in order to make sense of and situate their participants' lived experiences within the context of their life situation, the wider cultural and historical context, as well the specifics of the research situation (Finaly, 2011; Thompson, 2018). Taking a hermeneuticphenomenological approach, the researcher aims to 'grasp at the meaning' of the participants' sense-making (Churchill, 2018) while remaining true to the participants' experiences - as well as acknowledging and valuing the researcher's involvement in the 
research process (Finlay 2011). The researcher's humanness and situatedness in the world, including personal fore-understandings, beliefs and experiences, are considered prerequisites for empathising with and making sense of the participants' experiences (Finlay 2002b, Gemignani 2017).

\subsection{Recruitment and Sampling}

Ethical approval was granted by a University Ethics Committee. Seven participants were recruited in line with the small, homogenous sampling aims of Interpretative Phenomenological Research (Smith et al. 2009), and the wish to permit idiographic, in-depth data analysis. Participants (see Table 1) had recently experienced a first crisis in psychosis and were recruited via mental health charities, where they attended peer support groups. They were initially approached by peer support workers, who passed on letters of invitation to potential participants. Those who expressed an interest, were provided with an information sheet and consent form, and had the opportunity to discuss these with the first author prior to participation.

Table 1. Participant Information. Characteristics of Study Participants.

\begin{tabular}{|c|c|c|c|c|}
\hline $\begin{array}{l}\text { Participant } \\
\text { pseudonym }\end{array}$ & Age (years) & Gender & Ethnicity & Experiences \\
\hline Elias & $40-45$ & Male & White British & $\begin{array}{l}\text { Voices, unusual } \\
\text { beliefs }\end{array}$ \\
\hline Lola & $55-60$ & Female & $\begin{array}{l}\text { White Other } \\
\text { European }\end{array}$ & $\begin{array}{l}\text { Voices, visions, } \\
\text { unusual beliefs }\end{array}$ \\
\hline John & $25-30$ & Male & White Other & Unusual beliefs \\
\hline
\end{tabular}


European

\begin{tabular}{|c|c|c|c|c|}
\hline Henry & $60-65$ & Male & White British & $\begin{array}{l}\text { Voices, unusual } \\
\text { beliefs }\end{array}$ \\
\hline Matthew & $65-70$ & Transgender & Black British & $\begin{array}{l}\text { Voices, visions, } \\
\text { unusual beliefs }\end{array}$ \\
\hline Nina & $15-20$ & Female & $\begin{array}{l}\text { White } \\
\text { American }\end{array}$ & $\begin{array}{l}\text { Voices, visions, } \\
\text { unusual beliefs }\end{array}$ \\
\hline Mark & $35-40$ & Male & White British & $\begin{array}{l}\text { Voices, visions, } \\
\text { unusual beliefs }\end{array}$ \\
\hline
\end{tabular}

\subsection{Visual and Verbal Data Collection}

The aim of the data collection process was to generate multimodal data - verbal, visual, embodied - to provide insight into the participants' felt experiences. After providing written consent, participants took part in semi-structured interviews exploring their lived experiences. The interview scheduled was adapted from the phenomenological, semistructured interview developed by Boden and Eatough (2014) and was divided into three stages: expression, mapping and verbal exploration. Expression: Each interview began by inviting participants to think about their first crisis in psychosis and create an image that illustrated their felt experiences during crisis. Participants were given a selection of papers, pencils, coloured pencils, felt-tip pencils and crayons. Mapping: Once participants completed their drawings, they were guided through a process of exploring and interpreting parts of their image and their image as a whole. Verbal exploration: Participants were asked further open-ended and reflexive question regarding their experiences in crisis while the image 
remained a point of reference throughout this phase. Drawings can provide 'thick depiction' to support the 'thick description' of interviews (Kirova \& Emme 2006). They work at a metaphorical level and are directly intertwined with the embodied subjectivity of the drawer (Boden \& Eatough 2014), thus providing a non-linguistic way of capturing felt experience. Visual methods are becoming more commonplace within psychological research (Reavey 2012) and support participants to describe experiences that can seem to be 'beyond' words (Todres 2007), as well as reducing potential power differentials during interview, and supporting the production of participant-led data (Frith \& Harcourt 2007; Jones 2006). Drawings have previously been used successfully with this population (Attard et al. 2017; Rhodes \& Jakes 2010). Interviews were audio-recorded and transcribed, and electronic copies of the images were taken. Interviews lasted between 30 and 90 minutes. Five were conducted face-to-face, and two via Skype, due to travel constraints.

\subsection{Data Analysis}

Data were analysed using an expanded hermeneutic-phenomenological analysis (Boden \& Eatough 2014; Kirova \& Emme 2006) drawing on Interpretative Phenomenological Analysis methodology ([IPA] Smith et al. 2009) This is an idiographic method of inquiry that aims to describe, explore, and understand the lived experience of particular individuals in particular situations (Shaw 2010; Smith et al. 2009). The approach acknowledges that analysis involves interpretation, as the researcher attempts to make sense of the participant's sense-making (a 'double hermeneutic' or twofold sense-making process; Smith, 2011). Visual data was analysed using the Framework for the Analysis of Drawings developed by Boden and Eatough (2014). 
Interviews were analysed first individually, and then across cases, with attention being paid to both what the participant said, what they drew, and the dialogue between each aspect (Boden \& Eatough, 2014). Transcripts were read and re-read several times, and initial notes were taken on both the verbal and visual data. Emergent themes representing the participants' experiential claims and concerns were developed, and patterns and connections between emergent themes were identified. A thematic structure was produced for each participant, before these were integrated into one master table of themes that accounted for both visual and verbal data.

\subsection{Reflexivity}

Reflexivity is understood as the use of critical self-awareness and reflection to interrogate the ways in which the researcher's subjectivity, intersubjective dynamics, context and the research process itself have affected the generation of the research findings and their representation (Finlay 2017; Josselson 2017). While the existing literature shows that reflexivity promotes rigour, transparency and validity in qualitative research (Darawsheh 2014; Tuval-Mashiach 2017), the term remains a contested concept and there is a lack of consensus as to when, how and to what extent reflexivity should be integrated in the qualitative research process (Darawsheh 2014, Finlay 2017). Different typologies of reflexivit(ies) have been developed and are being debated within qualitative research (for an overview see Finlay 2017). For the purpose of this study, the authors adopted the view that meanings and knowledge are created and negotiated between the researcher and the research participant within a particular social context (Finlay 2002b). Drawing on Burkitt (2012), Finlay (2017) and Gemignani (2017), researcher subjectivity was seen as an opportunity rather than a hindrance. Throughout all stages of the research process, the 
authors critically reflected upon and examined the subjective and intersubjective elements that influenced the design of the study, the collection and analysis of the data, and the representation of the research findings (Finlay 1998; 2002a; 2002b). During the study design, the authors' motivations, interests, concerns and theoretical fore-understandings were explored. While the study was being undertaken, reflexive journaling and regular research team meetings paid close attention to the researchers' own feelings in a process of 'reflexive embodied empathy' (Finlay 2005). Reflections were integrated into the analysis and write-up of the study.

\section{Findings}

Three themes captured participants' experiences: 'It was like a lightning bolt hitting my world': Feeling shattered; 'That's really strange': An all-enveloping strangeness and lingering threat; and 'I was left stranded in the dark': Lacking a sense of belonging.

\section{1 'It Was Like a Lightning Bolt Hitting My World': Feeling Shattered}

In all cases, a first crisis in psychosis involved intense emotional distress owing to the suffering associated with both having unusual perceptual experiences, and historical or contemporary experiences of abuse. Participants experienced their crisis as a unique experience that involved a shattered sense of body-self ('deep inside you find it is all completely broken', Mark), a feeling of being trapped ('I wanted to be out of that being', Nina) and suicidal despair.

Elias captures the shocking and shattering quality most powerfully in his drawing of a lightning bolt destroying his world (see Figure 1):

It was like a lightning bolt hitting my world [...] It was like I couldn't escape from it. 
I didn't know what was happening as well. There was a psychology added to it, abuse

added to it, and I didn't know what was happening. It never happened to me before.

Like Elias, other participants described their first crisis as a sudden 'attack' (Mark) or 'shock' (Lola). For many, the crisis felt inseparable from historical (and occasionally contemporaneous) violence, abuse or neglect. For example, Elias explained that his first psychotic episode was triggered, and its horror reinforced by, an experience of sexual abuse.

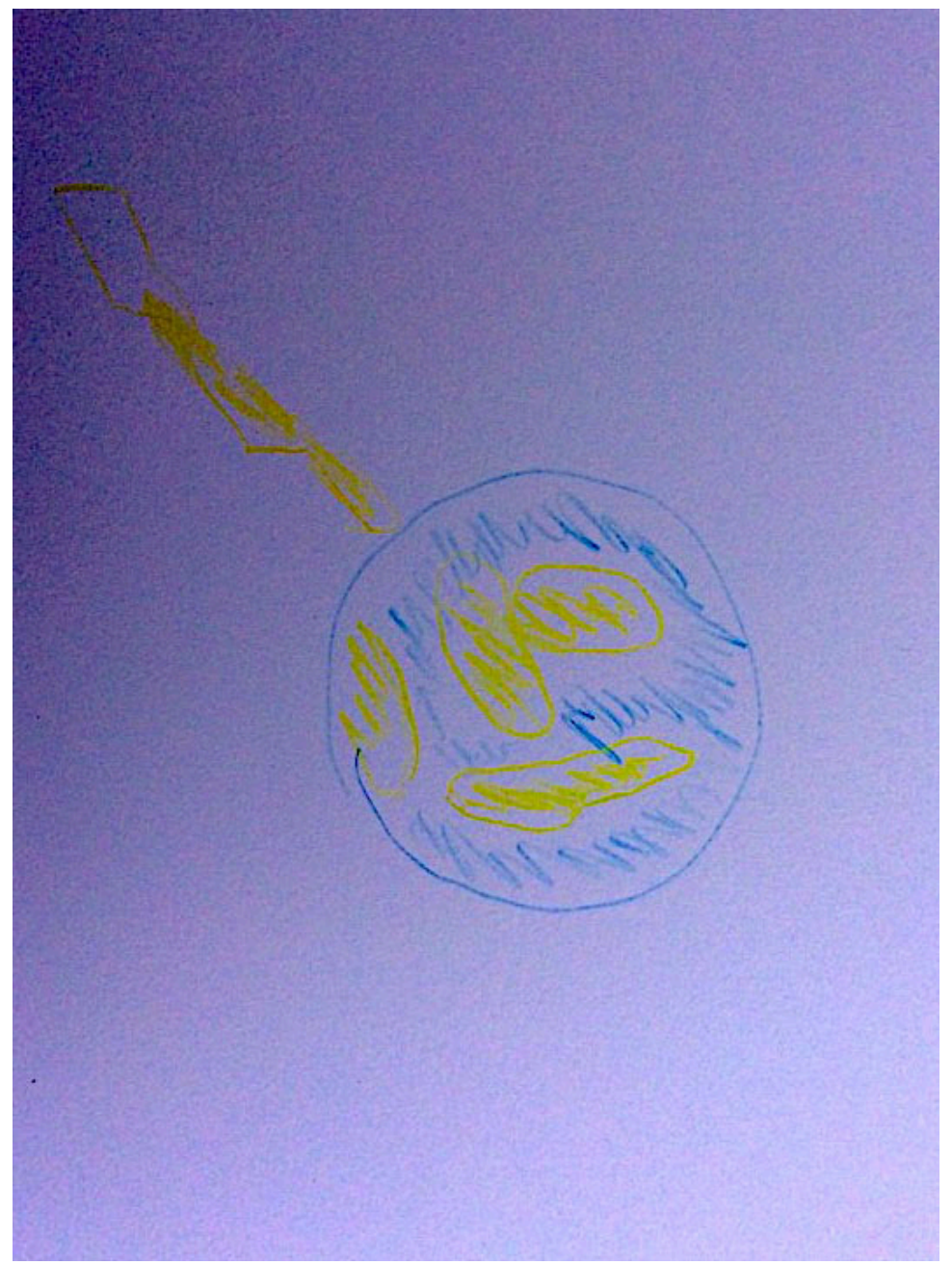

Figure 1. Elias' image. A sense of shattered existence in psychosis. Elias represented his first crisis in psychosis as a 'lightning bolt hitting my world'. He considered an experience of abuse 
to be at the core of his psychosis and described his first crisis in psychosis as a sudden, unintelligible 'attack' involving a feeling of disempowerment and the overwhelming urge to flee.

Similarly, Henry associated his first crisis in psychosis with emotional and physical abuse, which he re-lives in flashbacks:

[I was] pushed about, bullied, emotionally and physically abused [...] It would stop, it would - it would stop all my normal functions. [...] That's when it [hearing voices] first started. It was a horrific experience.

Nina described how even in her dreams her voices attacked her and she found no rest. She felt tortured by their omnipresence, harassing her verbally and causing her to feel physical pain. In itself, the psychosis 'felt like trauma':

[The voices - see Figure 4] were able to... create great, painful sensations in my arms and legs and in the whole of my body. [H]e also found that it was effective to go into my dreams and exact either torture methods or to hurt me sexually. 




Figure 4. Nina's image. 'Feelings and forces' constituting Nina's first crisis in psychosis.

Nina referred to her first crisis in psychosis as 'trauma' and drew the vocies she hears - 'love, impulse, duty and hatred' - as well as different feelings she experienced in relation to her voices: 'intense wrath, numbing horror, depression and then this dark tyrant attitude.' While the 'hatred' and 'horror' voice were harrassing Nina, she valued the 'love' voice which she referred to as her friend. Nina seemed unable to escape her voices, even in her dreams the 
voices attacked her and she found no rest. The omnipresence of Nina's voices, accounted for the feelings of fatigue she described constituting her first crisis in psychosis.

The sense of entrapment that Elias ('I couldn't escape from it') and Nina describe is also present in Matthew's account. He describes: 'Not going anywhere, that's what I feel [...] sort of hanging in limbo'. Matthew felt caught up in an uncertain, disempowering state ('I'm not powerful'), as he lingered between life and death, which he represents by drawing crosses at the centre of his image (Figure 3). Many participants described feeling suicidal or had attempted suicide during this time:

I [...] said I can't do this anymore...I had some suicidal ideations (Nina)

I wanted to go into the direction of total hopelessness and despair and kill myself (Mark)

All participants described the shattering nature of their first crisis, resulting in feelings of brokenness, and unspeakable suffering. Their language is apocalyptic: horror, torture, and entrapment. 


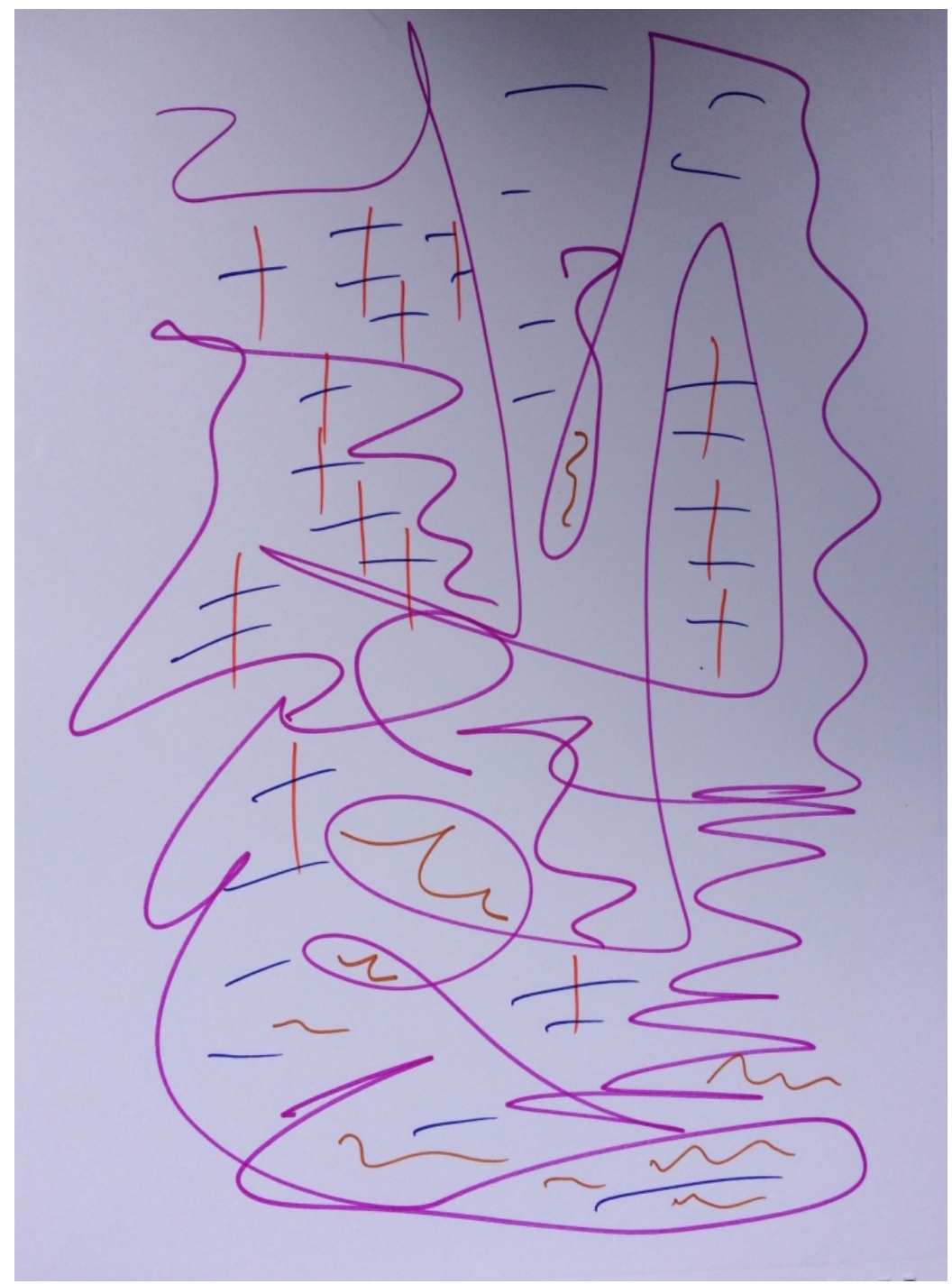

Figure 3. Matthew's image. Confusion, disorientation and fear of dying central to Matthew's first crisis in psychosis. Matthew drew floating, entangled lines encircling small crosses and waves, which represent death and afterlife to illustrate chaos, a sense of disorientation and fear of dying when in crisis.

2.2 'That's Really Strange': An All-Enveloping Strangeness and Lingering Threat 
Connected to the broken, shattered sense of self and world, former certainties were lost to an uncertain, uncanny atmosphere. This theme is subdivided into two aspects: feelings of disorientation and a lingering sense of threat.

2.2.1 'I didn't know what was happening': Feeling disoriented. An all-encompassing disorientation co-constituted a first crisis in psychosis in all cases, and rendered the participants' environment an alienating, stage-like scene, which they experienced as confusing and unreal. Elias describes this by saying: 'I didn't know what was happening'.

To Nina, the world appeared in a strange, indeterminable light ('nothing was exactly what it looked like'). Elias and Matthew wandered the streets lacking purpose and direction: 'then you're walking around not knowing what's going on' (Elias); 'I can't find my way around', (Matthew). As the participants came to inhabit a structure-less, chaotic world, they struggled to distinguish between the 'real' and the 'imagined': 'It was difficult to know what was true and what's not true' (John). Drawing floating, entangled lines (Figure 3), Matthew described a dissociative state where he lost awareness, and questioned his humanity:

I thought aliens were going to land and that's very common in schizophrenia. Wasn't sure whether or not I was an alien, I used to go into these trances, I still do it until this day. It's like being dazed. I come back...it's like losing your awareness, not blackouts, but it's like losing your awareness.

John also felt a sense of unreality, which he experienced as 'losing track of progress and actual meaning and reality'. As John's lifeworld unravelled, he felt detached from his surroundings, and came to perceive them as a stage-like, unpredictable scene: 
Like, it was a sort of play or a film or something that everyone else knew about and I didn't know about, something of that sort and so then you always felt like you were in an impossible situation [...] And some sort of charlatan.

This uncanniness was shared by all participants as their life-worlds collapsed, and former certainties were lost to disorientation and confusion, which Matthew describes by saying 'then it goes a bit haywire'. For most, a clear distinction between the 'real' and 'unreal' felt impossible.

2.2.2 'The world seemed scarier': feeling threatened. Owing to the strangeness and disorientation, all participants found themselves in constant anticipation of harm during their first crisis in psychosis. Henry described this as an 'air of danger'.

Nina reported feeling an all-enveloping, indefinable threat as the background orientation to her lifeworld. She describes a 'shiftiness' permeating the atmosphere and how 'everything sort of felt unsafe'. John also described a sense of omnipresent threat and mistrust:

'Yes, it just felt like you're being watched and perhaps people are following your every moves, so you have to be careful and very ... I guess there's also a feeling of ... Like I was always a bit scared and frightened of everything that I encountered.

The lingering threat had an indefinable quality; it is a 'strange fear' but with a 'very real sort of presence' (Nina). Most participants found it difficult to name what they were afraid of: 'You know, that sort of random experience of fear. What am I really frightened of?' (Henry). All described how intense fear predominated: 'I was very frightened.' (Matthew); 'I was super, super frightened.' (Nina). In Elias' case, overwhelming anxiety culminated in a panic 
attack: 'You start shaking. Your chest starts fluttering. You get shortness of breath. Then you're paranoid'.

In crisis, the participants' lived worlds lost their familiar structure, leaving them feeling unsafe and overwhelmingly frightened.

\section{3 'I Was Left Stranded in The Dark’: Lacking a Sense of Belonging}

All participants reported feeling lonely and disconnected from others. They craved social connectedness, but for some, this only increased the sense of threat and fearfulness. Four participants described the need to withdraw from others. In crisis, Elias felt hurt and alone: 'left stranded in the dark'. The abusive behaviour he had suffered seemed to have eroded his sense of basic trust in others as benevolent and predictable social beings:

I couldn't understand why people were doing what they were to me, doing what they did to me. So like everyone treated me pretty awfully. So like I didn't know what was happening. That made me think I've done something wrong and I never did anything wrong.

As Elias lost trust in others, he experienced social relations as potentially threatening, and felt the need to withdraw. Mark also expressed the need to avoid others. His drawing depicts himself smiling behind prison bars (see Figure 2.1). Mark explained that he would like to build a wall around himself to protect him from others:

I thought if I had no people around me, like just me, just me like that and then all these people [draws stick people - Figure 2.1, bottom centre]. That could be like my family and stuff and my friends and the group members. I would like to build like a 
wall that would protect me so I would just be like that in this whole thing [draws a line that separates himself from others - Figure 2.1, bottom centre].

Mark described feeling forsaken in crisis, as God, whom he trusted, had abandoned him and watched him suffer: 'Why has God allowed me to suffer like this? Why has he allowed all this suffering?'. As Mark's trust in God as a benevolent saviour was shattered, his life-world became a confusing ('I can't quite figure out the puzzle' - Figure 2.2) and surreal place ('sometimes reality is not quite correct in some ways').
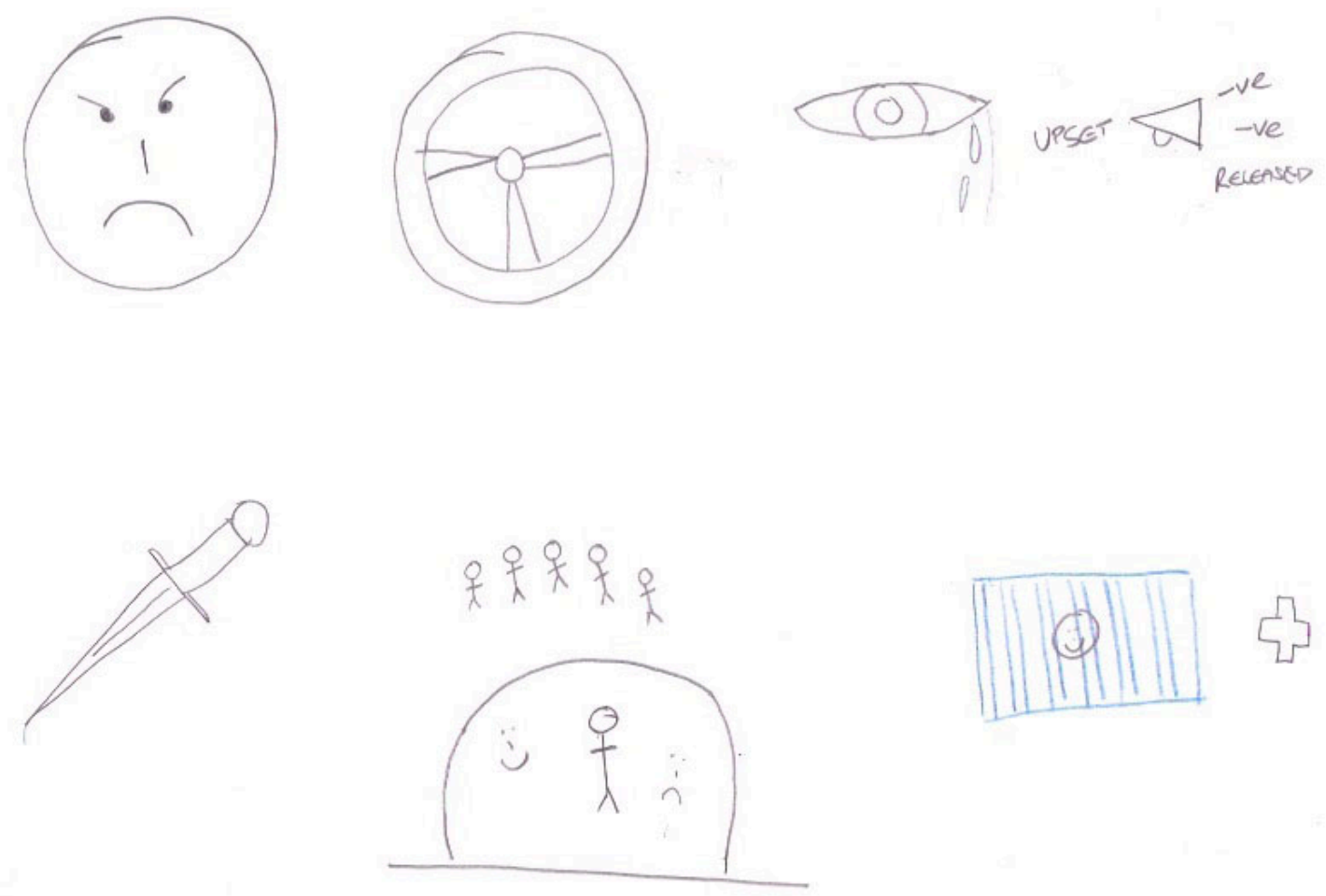

Figure 2.1. Mark's first image. Anger, sadness, isolation and loneliness permeated Mark's first crisis in psychosis. Mark drew an angry face and a steering wheel representing a feeling of uncontrollable anger preceding his first crisis in psychosis. He also drew a crying eye and explained that he felt very sad and upset in crisis. Crying helped him release these feelings: 'If 
you have a cry, it's like a megaphone. Then all this upset and negativity is released.' He drew a knife representing the his voices' harassing comments. His voices accused him of having killed several people. Mark drew himself as a stick figure and explained that he would like to build a wall around him to protect himself from other people. Mark expressed the need to isolate himself from others and drew a picture depicting himself smiling behind prison bars 


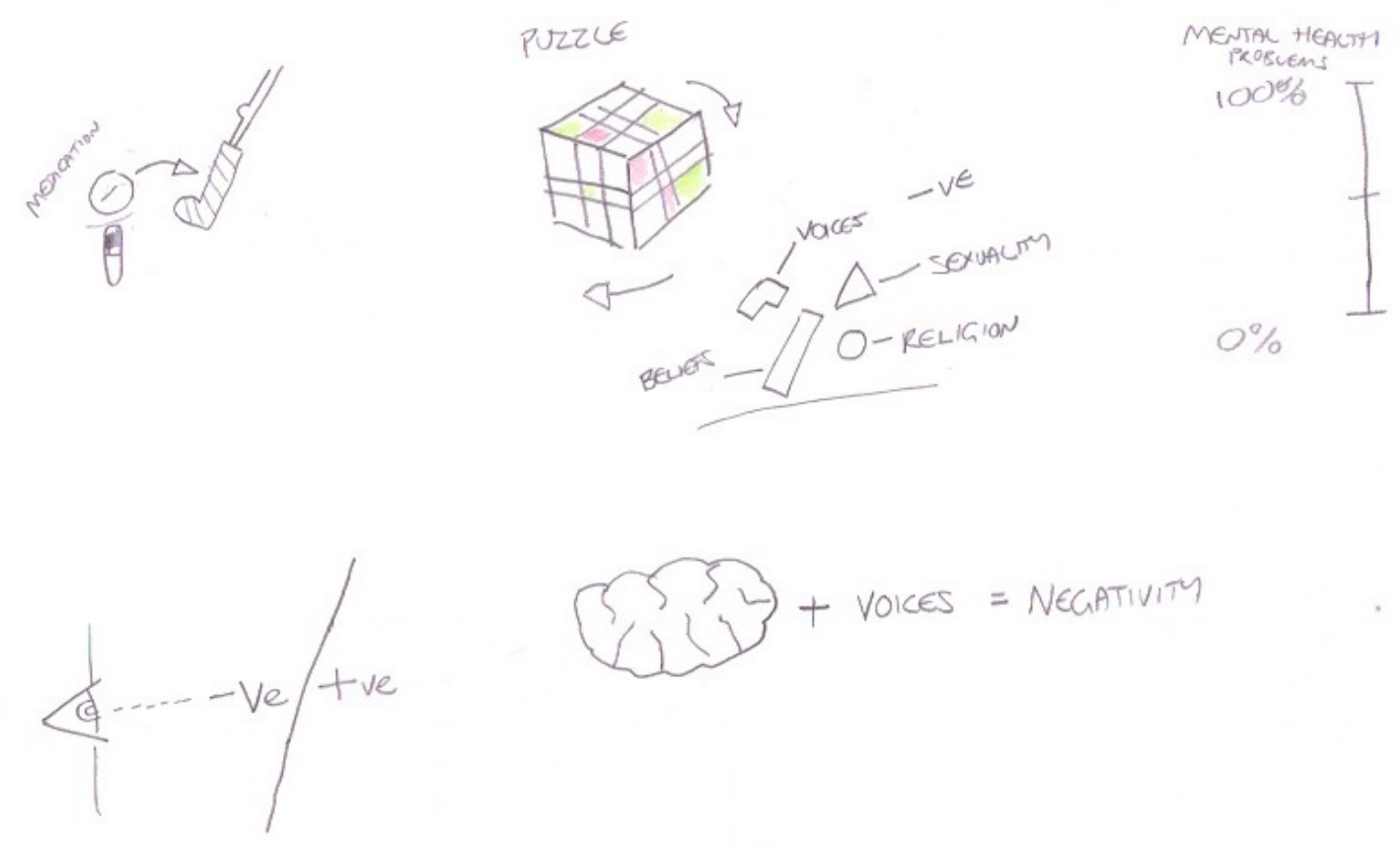

Figure 2.2. Mark's second image. Feeling broken, confused and overwhelmed by negative thoughts. Mark drew a broken leg in a plaster cast. In crisis, Mark felt 'emotionally broken' and was prescribed antipsychotic medication, which to him feels like 'the doctors try and fix your broken leg'. He also drew a Rubik's cube to illustrate the all-pervasive confusion predominating his first experience of psychosis. The cube's mismatching pieces resemble different 'bits' that constitute his distress: 'You can't quite figure out the puzzle because the puzzle is so difficult. I just wish I could put all those bits together and figure it all out'. Mark identified his voices as part of the problem, but he struggled to understand how the other 'bits' - his 'negative sense of self, being homosexual and having strong religious beliefs' - fit into the bigger picture. Mark represented his 'negative sense of self' by drawing an eye that looks at a negative sign. Mark's voices turn his 'jump on negative thoughts and turn them 
into complete negativity'. The scale Mark drew shows that 'some people have more mental health problems than others.'

Henry described how he felt isolated, and physically isolated himself from others, because of what he was experiencing: 'You're trying to deal with the issues and the pain that goes with it is...is excruciating. Because you think, I'm on my own.'. In crisis, Henry came to inhabit a solitary experiential realm, to which he felt no one could relate: 'You know, there's no one here like me.'. Similarly, Matthew described a sense of disengagement and alienation from others and the world:

I didn't think I was part of it [the world], I didn't think I was ever going to get better. I didn't think anybody understood me, I felt alone, I wanted to achieve in the world, but didn't think I ever would.

Emotionally deprived, Matthew longed for connectedness and love, which he experienced as an embodied craving and described as feeling 'hungry':

I've been hungry...for life, for hope, recovery, to find my place in the world, hungry for love. I mean hunger is a basic need that needs to be ... it's to be ... everybody needs ... hungry for attention, everything.

Participants had lost trust in the world and others. Several participants expressed the need to isolate themselves as others were perceived as imminent and existential threats. Their fearfulness and sense of abandonment was contrasted with a desire for connectedness and belonging. 


\section{Discussion}

Participants in this study experienced their first crisis in psychosis as shattering, undermining their sense of themselves as a connected, situated, embodied self. In most cases, their experiences of abuse, were inseparably entangled with their unusual perceptual experiences, causing extreme distress - horror, fear, and a sense of entrapment. The crisis was experienced as a psychological shock. Participants lost basic trust in in the world and struggled to have any sense of ontological certainty. They felt enveloped in a strange, uncanny atmosphere, and constantly unsafe and under threat. They felt alone with these experiences, alienated and afraid of others, lacking any secure sense of connectedness or belonging in the world. This study illustrates how, for these individuals, their felt experience was significant, meaningful and central to their experience of being in crisis.

\subsection{The Delusional Mood Revisited}

This study illustrated how a crisis unfolds across the full range of felt experiences. Fuchs (2013) argues that there are five layers of feeling, including mood and atmosphere, a felt sense of vitality or wellbeing, existential feelings (Ratcliffe 2008), such as the feeling of being 'at home', and emotions. Participants in this study described altered feeling states at all five of these levels.

Participants in this study particularly noted feeling the world was strange and unreal during their first crisis, describing feeling enveloped in an atmosphere of disorienting and threatening strangeness. This echoes Jaspers' (1963) existential-phenomenological description of the 'delusional mood'. He claimed that a feeling of unreality is central to the 'delusional mood', an all-pervasive strangeness, where things appear 'somehow' different and not quite 'real' (Ratcliffe 2013, p.5). Jaspers states that unusual perceptual phenomena 
are the individual's attempt to make sense of the ineffable change, uncertainty, and tension felt within the context of the 'delusional mood'. To reduce the innate feeling of all-pervasive, unpleasant uncertainty, the individual searches for a 'fixed point' to 'cling' to and arrives at an unusual belief (Jaspers, 1963, p.98). This is an accepted clinical phenomenon (Sass \& Pienkos 2013), however, the concept remains problematic, as it does not account for the heterogeneity of unusual perceptual experiences, neglects their content, and dismisses them as unintelligible (Radden 2011; Ratcliffe 2013; Sass \& Pienkos 2013). In line with these more contemporary views (Bentall 2004), the participants' accounts suggest they felt confused and unreal, but, at least now, hold broadly comprehensible explanations for their psychotic experiences, namely abuse, mistreatment, and neglect.

\subsection{Shattered Existence and the Loss of 'One-Place-Trust'}

Confirming the existing literature, traumatic experiences shaped the form and content of the participants' psychotic experiences (Read et al. 2005). At the subjective, and affective, level, these experiences were entirely intertwined and deeply distressing. Historically, health professionals often dismissed trauma reports in psychosis as 'delusional' (Seedat et al. 2003; Tarrier 2005), and have not recognised or treated post-traumatic stress (Kilcommons \& Morrison 2005), however, this is changing (Mueser et al. 2010). Contradicting Jaspers (1963) and common psychiatric assumptions (Kapusta 2014), the form and content of the participants' unusual experiences seem to mirror their interpersonal trauma, suggesting their experiences are intelligible, meaningful human reactions to shattering life experiences. This reflects the views of the service-user movement (Romme et al. 2009).

Participants in this study also reported their psychotic experiences to be traumatising in their own right. Some evidence points towards a causal relationship between psychosis (and 
hospitalisation) and post-traumatic stress (PTSD) (Morrison et al. 2003, Ratcliffe, Ruddell, \& Smith 2014). A recent review found psychosis-related PTSD rates between $11 \%$ and $67 \%$, and noted that trauma history is additionally associated with psychosis-related PTSD (Berry et al. 2013).This idea also been supported by emerging qualitative research, which describes a psychotic breakdown as an "emotional earthquake" followed by intense self-blame and selffragmentation (Hutchins et al. 2016, p.20), or as a rupture in the life-story or self-narrative (Davidson \& Roe 2007). This study echoes that idea by emphasising the unexpected and disorienting nature of crisis.

One way to understand the feeling of being shattered is as ontological insecurity (Laing, 2010) or a felt loss of 'one-place-trust' (Janoff-Bulman 2010). This is a profound mistrust in the world, undermining the most basic assumptions about the benevolence of others and safety of the environment (Janoff-Bulman 2010). From a phenomenological perspective, Ratcliffe (2017) argues that a loss of basic trust in others must necessarily affect the individual's self-confidence, including trust in her abilities, activities and thoughts, which in turn can lead to isolation and anxiety, as evidenced in this study.

\subsection{Loneliness and 'Unhomeliness' in Psychosis}

A felt-experience of uncanniness and the absence of a previously taken-for-granted feeling of 'one-place-trust', leads to a disruption in everyday attunement to the world and others (Heidegger 1962). This is the loss of tacit, pre-reflective significance, familiarity, and belongingness (Ratcliffe 2008). In crisis, the person no longer feels at-home-in-the-world (Ratcliffe 2013), and specifically feels disembedded from the shared world and disconnected, or alienated, from others. Warm and caring interpersonal relationships give rise to a sense of belonging, and are vital to human well-being (Baumeister \& Leary 1995; Reis \& Gable 2003; 
Van Harmelen et al. 2017), and the relationship between social isolation and severe mental distress has been supported by numerous studies (Reininghaus et al. 2008; Palumbo et al. 2015). Loneliness, social isolation, and a lack of solidarity have been identified as fundamental problems in psychosis (Da Rocha et al. 2018; Morgan et al., 2005; Sündermann et al. 2014; Windell, Norman \& Malla 2012). Previous research has associated long-standing psychosis with social isolation and small social networks (Gayer-Anderson \& Morgan 2013). However, the mechanisms through which loneliness and social isolation interacts with psychosis have been poorly understood.

This study suggests there are complex relationships between the loss of 'one-place-trust', the formation of unusual experiences and a disruption of the individual's sense of belonging. Trust is an intersubjective and reciprocal phenomenon (Ratcliffe 2017), and the experience of losing trust is co-created and reinforced by experiences of social exclusion, stigma, and marginalisation that are common in mental health contexts (Hinshelwood 2013). These effectively demonstrate a lack of trust in the person, deeming them untrustworthy. People experiencing a psychotic crisis inhabit a world where they fear to trust and where they do not dare to establish or maintain social relations (Attard et al. 2017; Birchwood 2003; Fett et al. 2016). Beliefs are no longer anchored to a shared world and 'delusional' thinking becomes more likely (Ratcliffe 2017). In isolation, the individual more readily accepts the emergence of unusual perceptual phenomena, peculiar significances and abstract linkages between free-floating elements in her environment (Ratcliffe 2017). A breakdown in trust and trustworthiness has been shown to form a fundamental part of the suicidal process (Benson et al. 2013), and there is an elevated risk of suicide after a first episode of psychosis (Robinson et al. 2010). This was reflected in the suicidal feelings described in this study. It is therefore vital to address and promote the development of social support and inclusion 
early in psychosis - something which Early Intervention Services in the UK are working towards. However, social network interventions, such as Open Dialogue and Networkfocused nursing, peer support, and family and group therapies, or community-based support groups (such as Hearing Voices groups) may help to restore a sense of belonging and trust in others.

\section{Evaluation of the Approach}

Hermeneutic-phenomenological research draws on rich, first-person accounts of idiographic experience and meanings (Smith et al., 2009) to explore and understand subjective experience and psychosocial processes (Larkin \& Thompsons, 2012). However, hermeneuticphenomenological research is significant beyond a focus on the individual, as 'acquaintance with the particulars is the beginning of all knowledge scientific or otherwise' (Allport, 1942, p. 56) and brings us closer to the universal (Smith et al. 2009; Warnock 1987). By providing detailed idiographic information, phenomenological research has the potential to situate and understand a phenomenon and the individual in the socio-cultural context, nourish mutual understanding and enliven dialogue, interpret quantitative findings and re-evaluate existing knowledge (Larkin \& Thompson 2012; Smith \& Osborn 2015b; Smith et al. 2009).

Researcher subjectivity and interpretation are considered fundamental and highly valuable in phenomenological research. Within the hermeneutic-phenomenological tradition, it is understood that through our bodily enmeshment with the world we are already interpreting as we perceive (Merleau-Ponty, 1962) and all understanding is consequently mediated by interpretation (Moran \& Mooney, 2002). However, phenomenology acknowledges that the world as it is experienced by the researcher is different to how it is experienced by the researched and therefore all descriptions and interpretations made by the researcher need 
to be firmly grounded in participants' accounts. Critical self-awareness and continuous reflection regarding the researcher's subjectivity, vested interests, pre-existing knowledge and ready-made interpretations are necessary to disentangle these from the participants' descriptions (Finlay, 2009). The challenge for the researcher is to avoid self-absorption regarding their experiences, understandings and feelings while simultaneously using them to empathise with and get closer to the participants' lifeworlds (Finlay 2009). One way of avoiding this pitfall is to embrace the research encounter as a relational and intersubjective process where knowledge is co-created by the researcher and the researched (Finlay, 2005; Zahavi, 2001).

IPA is a well-established method of qualitative inquiry committed to phenomenological, idiographic and hermeneutic principles (Smith 2011). Since its development in the mid1990s, IPA has become one of the most influential and widely used qualitative methods in psychology and health research (Cronin \& Lowes 2016; Eatough \& Smith 2017). IPA has been criticised for not adhering to a strict set of analytical rules (Smith \& Osborn 2004); however, Smith et al. (2009), the founders of the method, argue that this is in fact one of the method's advantages. IPA is not intended to be prescriptive and can be flexibly tailored to the researcher's individual way of working and their reflexive process while still meeting the established quality criteria for qualitative research (Smith 2011; Smith \& Osborn 2004). IPA, and qualitative research methods more broadly, have been further criticised for being heavily language-based (Boden \& Eatough 2014). Questions have been raised as to whether verbal data alone can capture the fullness and richness that characterises human lived experience (Reavey \& Johnson 2017). Thus, the use of visual and creative methods in qualitative research has seen a surge over the past three decades (Reavey 2012). The use of visual methods has been shown to aid the exploration of embodied, pre-reflective and 
sensory layers of experience that cannot easily be verbalised (Boden \& Eatough 2014). However, images are heterogenous, ambiguous and polysemic (Bailey \& McAtee 2003) and the researcher's interpretation of the image produced by the participant needs to be carried out critically and reflexively. The interpretation of the image presented by the researcher must reflect the participant's meanings, associations and interpretations, and should not draw on archetypes, symbols or conceptual metaphors (Boden et al. 2019; Lakoff \& Johnson 2003).

\section{Conclusions}

This study has highlighted the complexity, significance, and meaningfulness of the felt experiences associated with a first crisis in psychosis. A sudden shattering shock, a fearful atmosphere and feelings of mistrust were particularly implicated, and were experienced in parallel to their unusual perceptions and beliefs. These feelings were intertwined with traumatic memories, resulting in feelings of being stranded and no longer at-home-in-theworld.

Services integrating trauma-informed care (Muskett, 2013) into the treatment of psychosis, including routine trauma assessments and treatment for PTSD symptoms (both as a result historical and psychosis-related trauma), are likely to benefit those experiencing crises, and promote longer-term recovery, and is in line with current NICE guidelines (2014) in the UK. With fear so figural in the crisis experience, inpatient and community services that attempt to provide physically and psychologically safe and calm environments, provide opportunities 
to be with others on their own terms, and which prioritise establishing trusting and stable therapeutic relationships may better support recovery. In the inpatient context, quiet rooms, creative outlets, more permeability for friends and family (Attard et al. 2017) and opportunities to be in fluid, outdoor spaces that afford greater possibility for action and social connection (McGrath \& Reavey, 2015) may all be supportive.

Services that consider the person holistically, taking account of how they view others, the world and themselves, which see 'symptomatology' as meaningful experience, and which consider the feelings and emotions of the service-user as something to be acknowledged and explored, rather than solely medicated, may also offer longer-term benefit by enabling people to feel safe enough to reconstruct their sense of self as a social being.

\section{Declaration of Interest}

The authors report no conflicts of interest. The authors alone are responsible for the content and writing of the article.

\section{References}

Allport, GW, 1942, The use of personal documents in psychological science, Social Science Research Council (Bulletin No. 49), New York, NY.

American Psychiatric Association, 2013, Diagnostic and statistical manual of mental disorders: DSM-5, 5th edn, Arlington, VA, American Psychiatric Association. 
Amering, M 2009, 'Preface: Recovery is reshaping our clinical and scientific responsibilities', in M Romme, S Escher, J Dillon, D Corstens \& M Morris (eds.), Living with voices: 50 stories of recovery, PCCS Books Ltd, Herefordshire, UK.

Andersen, SM \& Chen, S 2002, 'The relational self: an interpersonal social-cognitive theory', Psychological review, vol. 109, no. 4, p.619, doi: 10.1037//0033-295X.109.4.619

Attard, A, Larkin, M, Boden, Z \& Jackson, C 2017, 'Understanding adaptation to first episode psychosis through the creation of images', Journal of Psychosocial Rehabilitation and Mental Health, vol. 4, no. 1, pp.73-88. https://doi.org/10.1007/s40737-017-0079-8

Bailey, J \& McAtee, D 2003, 'Another Way of Telling': The Use of Visual Methods in Research, International Employment Relations Review, vol. 9, no. 1, pp.45-60.

Baumeister, RF, \& Leary, MR 1995, 'The need to belong: desire for interpersonal attachments as a fundamental human motivation', Psychological Bulletin, vol. 117, no. 3, p. 497.

Benson, O, Gibson, S, Boden, Z \& Owen, G 2013, 'Exhausted without trust and inherent worth: A model of the suicide process based on experiential accounts', Social Science \& Medicine, vol. 163, pp. 126-134. https://doi.org/10.1016/j.socscimed.2016.06.045

Bentall, RP 2004, Madness explained: Psychosis and human nature, Penguin UK, London, UK.

Bentall, RP, Corcoran, R, Howard, R, Blackwood, N \& Kinderman, P 2001, 'Persecutory delusions: a review and theoretical integration', Clinical psychology review, vol. 21, no. 8, pp.1143-1192. https://doi.org/10.1016/S0272-7358(01)00106-4

Berry, K, Ford, S, Jellicoe-Jones, L and Haddock, G 2013, 'PTSD symptoms associated with the experiences of psychosis and hospitalisation: a review of the literature', Clinical Psychology Review, vol. 33, no. 4, pp.526-538. https://doi.org/10.1016/j.cpr.2013.01.011 
Birchwood, M 2003, 'Pathways to emotional dysfunction in first-episode psychosis', The British Journal of Psychiatry, vol. 182, no. 5, pp.373-375. https://doi.org/10.1192/bjp.182.5.373

Birchwood, M, Connor, C, Lester, H, Patterson, P, Freemantle, N, Marshall, M, Fowler, D, Lewis, S, Jones, P, Amos, T \& Everard, L, 2013, 'Reducing duration of untreated psychosis: care pathways to early intervention in psychosis services', The British Journal of Psychiatry, vol. 203, no. 1, pp.58-64.

Birchwood, M, Meaden, A, Trower, P \& Gilbert, P 2002. 'Shame, humiliation, and entrapment in psychosis: a social rank theory approach to cognitive intervention with voices and delusions', in AP Morrison (ed.), A Casebook of Cognitive Theory for Psychosis, Brunner-Routledge. Hove, UK, pp. 108-131.

Boden, ZVR \& Eatough, V 2014, 'Understanding more fully: A multimodal, hermeneuticphenomenological approach', Qualitative Research in Psychology, vol. 11, no. 2, pp. 160-177. https://doi.org/10.1080/14780887.2013.853854

Boden, Z, Larkin, M \& lyer, M 2019, 'Picturing ourselves in the world: Drawings, interpretative phenomenological analysis and the relational mapping interview', Qualitative Research in Psychology, vol. 16, no. 2, pp.218-236. https://doi.org/10.1080/14780887.2018.1540679

Brocki, JM \& Wearden, AJ 2006, 'A critical evaluation of the use of interpretative phenomenological analysis (IPA) in health psychology', Psychology and Health, vol. 21, no. 1, pp., 87-108. https://doi.org/10.1080/14768320500230185

Brunet, K, Birchwood, M, Upthegrove, R, Michail, M \& Ross, K 2012, 'A prospective study of PTSD following recovery from first-episode psychosis: The threat from persecutors, voices, and patienthood', British Journal of Clinical Psychology, vol. 51, no. 4, pp.418433. https://doi.org/10.1111/j.2044-8260.2012.02037.x 
Burkitt, I 2012, 'Emotional reflexivity: Feeling, emotion and imagination in reflexive dialogues', Sociology, vol. 46, no.3, pp.458-472. https://doi.org/10.1177/0038038511422587

Carr, ER, McKernan, LC, Hillbrand, M \& Hamlett, N 2017, 'Expanding traditional paradigms: An integrative approach to the psychotherapeutic treatment of psychosis', Journal of Psychotherapy Integration, vol. 28, no. 2, 154-170. http://dx.doi.org/10.1037/int0000083

Chadwick, PK 2007, 'Peer-professional first-person account: Schizophrenia from the inside Phenomenology and the integration of causes and meanings', Schizophrenia Bulletin, vol. 33, no. 1, pp. 166-173. https://doi.org/10.1093/schbul/sbl034

Churchill, SD 2018, 'Explorations in teaching the phenomenological method: Challenging psychology students to "grasp at meaning" in human science research', Qualitative Psychology, vol. 5, no. 2, pp. 207-227. https://doi.org/10.1037/qup0000116

Conrad, K. (1958). Die beginnende Schizophrenie. Versuch einer Gestaltanalyse des Wahns, Thieme Verlag, Stuttgart, Germany.

Cronin, CJ \& Lowes, J 2016, 'Brief Encounters with Qualitative Methods in Health Research: Phenomenology and Interpretative Phenomenological Analysis', Cumbria Partnership Journal of Research Practice and Learning, vol. 5, no. 1, pp. 8-12.

Da Rocha, BM, Rhodes, S, Vasilopoulou, E \& Hutton, P, 2018, 'Loneliness in Psychosis: A Meta-analytical Review', Schizophrenia Bulletin, vol. 44, no. 1, pp. 114-125. https://doi.org/10.1093/schbul/sbx036

Darawsheh, W 2014, 'Reflexivity in research: Promoting rigour, reliability and validity in qualitative research', International Journal of Therapy and Rehabilitation, vol. 21, no. 12, pp.560-568. https://doi.org/10.12968/ijtr.2014.21.12.560 
Davidson, L. 2016, 'The recovery movement: Implications for mental health care and enabling people to participate fully in life', Health Affairs, vol. 35, no. 6, pp.10911097. https://doi.org/10.1377/hlthaff.2016.0153

Davidson, L \& Roe, D 2007, 'Recovery from versus recovery in serious mental illness: One strategy for lessening confusion plaguing recovery', Journal of Mental Health, vol. 16, no. 4, pp.459-470. https://doi.org/10.1080/09638230701482394

Deegan, P 1996, 'Recovery as a journey of the heart', Psychiatric rehabilitation journal, vol. 19, no. 3, p.91. https://psycnet.apa.org/doi/10.1037/h0101301

Deegan, PE 2008, 'Recovery as a self-directed process of healing and transformation', Occupational Therapy in Mental Health, vol. 17, no. 3-4, pp.5-21. https://doi.org/10.1300/J004v17n03_02

Dillon, J 2010, 'The tale of an ordinary little girl', Psychosis, vol. 2, no. 1, pp.79-83. https://doi.org/10.1080/17522430903384305

Dilthey, W 2002, Selected works (Vol. 3), The formation of the historical world in the human sciences, Princeton University Press, Princeton, NJ.

Dunkley, JE, Bates, GW \& Findlay, BM, 2015, 'Understanding the trauma of first-episode psychosis', Early intervention in psychiatry, vol., 9, no. 3, pp.211-220. https://doi.org/10.1111/eip.12103

Dutta, R, Murray, RM, Hotopf, M, Allardyce, J, Jones, PB \& Boydell, J 2010, 'Reassessing the long-term risk of suicide after a first episode of psychosis', Archives of general psychiatry, vol. 67, no. 12, pp.1230-1237, doi:10.1001/archgenpsychiatry.2010.157.

Eatough, V \& Smith, JA 2017, 'Interpretative Phenomenological Analysis', in C Willig \& WS Rogers (eds.), The SAGE handbook of qualitative research in psychology, Sage, London, UK, pp.179-193. 
Ellison, ML, Belanger, LK, Niles, BL, Evans, LC \& Bauer, MS 2018, 'Explication and definition of mental health recovery: A systematic review', Administration and Policy in Mental Health and Mental Health Services Research, vol. 45, no. 1, pp.91-102, doi: 10.1007/s10488-016-0767-9.

Fett, AK, Shergill, SS, Korver-Nieberg, N, Yakub, F, Gromann, PM \& Krabbendam, L 2016, 'Learning to trust: trust and attachment in early psychosis', Psychological medicine, vol. 46, no. 7, pp.1437-1447. https://doi.org/10.1017/S0033291716000015

Finlay, L 1998, 'Reflexivity: an essential component for all research? ', British Journal of Occupational Therapy, vol. 61, no. 10, pp.453-456. http://dx.doi.org/10.1177/030802269806101005

Finlay, L 2002a, 'Negotiating the swamp: the opportunity and challenge of reflexivity in research practice', Qualitative research, vol. 2, no. 2, pp.209-230. http://dx.doi.org/10.1177/146879410200200205

Finlay, L. 2002b, "'Outing" the researcher: The provenance, process, and practice of reflexivity', Qualitative health research, vol., 12, no. 4, pp.531-545. http://dx.doi.org/10.1177/104973202129120052

Finlay, L 2005, '"Reflexive embodied empathy": A phenomenology of participant-researcher intersubjectivity', The Humanistic Psychologist, vol. 33, no. 4, pp.271-292. http://psycnet.apa.org/doi/10.1207/s15473333thp3304_4

Finlay, L 2009, 'Debating phenomenological research methods', Phenomenology \& Practice, vol. 3, no. 1, pp. 6-25. https://doi.org/10.1007/9789460918346_003

Finlay, L 2011, Phenomenology for therapists: Researching the lived world, John Wiley \& Sons, Chichester, UK. 
Finlay, L 2014, 'Engaging Phenomenological Analysis', Qualitative Research in Psychology, 11, vol. 2, pp.121-141. https://doi.org/10.1080/14780887.2013.807899

Finlay, L 2017, 'Championing "reflexivities"'. Qualitative Psychology, vol. 4, no. 2, p.120. http://dx.doi.org/10.1037/qup0000075

Freeman, D 2007, 'Suspicious minds: the psychology of persecutory delusions', Clinical psychology review, vol. 27, no. 4, pp.425-457. https://doi.org/10.1016/j.cpr.2006.10.004

Freeman, D \& Garety, PA 2003, 'Connecting neurosis and psychosis: the direct influence of emotion on delusions and hallucinations', Behaviour research and therapy, vol. 41, no. 8, pp.923-947. 923-947. http://dx.doi.org/10.1016/S0005-7967(02)00104-3

Frith, H \& Harcourt, D 2007, 'Using photographs to capture women's experiences of chemotherapy: Reflecting on the method', Qualitative health research, vol. 17, no 10, pp.1340-1350. http://dx.doi.org/10.1177/1049732307308949

Fuchs, T 2013, 'The phenomenology of affectivity', in KWM Fulford, M Davies, R Gipps, G Graham, J Sadler, G Stanghellini \& T Thornton (eds.), The Oxford handbook of philosophy and psychiatry, Oxford University Press, Oxford, UK, pp. 612-631.

Garety, PA, Kuipers, E, Fowler, D, Freeman, D \& Bebbington, PE 2001, 'A cognitive model of the positive symptoms of psychosis', Psychological medicine, vol. 31, no. 2, pp.189195. https://doi.org/10.1017/S0033291701003312

Garfield, D, Simon, EK \& Ramachandran, A 2013, 'Psychosis and the human affective environment', in A Gumley, A Gillham, K Taylor \& M Schwannauer (eds.), Psychosis and Emotion, Routledge, Hove, UK, pp. 23-40. 
Gayer-Anderson, C \& Morgan, C 2013, 'Social networks, support and early psychosis: a systematic review', Epidemiology and Psychiatric Sciences, vol. 22, no. 2, pp.131-146. http://dx.doi.org/10.1017/S2045796012000406

Gelling, L 2015, 'Qualitative research', Nursing Standard, vol. 29, no. 30, pp. 43-47. http://dx.doi.org/10.7748/ns.29.30.43.e9749

Gemignani, M 2017, 'Toward a critical reflexivity in qualitative inquiry: Relational and posthumanist reflections on realism, researcher's centrality, and representationalism in reflexivity', Qualitative Psychology, vol. 4, no. 2, p.185. http://dx.doi.org/10.1037/qup0000070185

Goodliffe, L, Hayward, M, Brown, D, Turton, W \& Dannahy, L 2010, 'Group person-based cognitive therapy for distressing voices: views from the hearers', Psychotherapy Research, vol. 20, no. 4, pp.447-461. https://doi.org/10.1080/10503301003671305

Gumley, A, Gillham, A Taylor, K \& Schwannauer, M, 2013, 'Psychosis and emotion: the role of emotions in understanding psychosis, therapy and recovery', in A Gumley, A Gillham, K Taylor \& M Schwannauer (eds.), Psychosis and Emotion, Routledge, Hove, UK, pp. 1-9.

Hanssen, M, Bak, M, Bijl, R, Vollebergh, W \& van Os, J (2005), 'The incidence and outcome of subclinical psychotic experiences in the general population', British Journal of Clinical Psychology, vol. 44, no. 2, pp. 181-191. http://dx.doi.org/10.1348/014466505X29611

Heidegger, M 1962, Being and Time, trans. J Macquarrie \& E Robinson, Blackwell, Oxford, UK.

Henriksen, MG \& Parnas, J 2012, 'Clinical manifestations of self-disorders and the Gestalt of schizophreniav, Schizophrenia Bulletin, vol. 38, no. 4, pp. 657-660. https://doi.org/10.1093/schbul/sbs033 
Hickman, G, Newton, E, Fenton, K, Thompson, J, Boden, ZVR \& Larkin, M, 2015, 'The experiential impact of hospitalisation: Parents' accounts of caring for young people with early psychosis', Clinical child psychology and psychiatry, vol. 21, no. 1, pp.145155. https://doi.org/10.1177/1359104515581716

Hinshelwood, RD 2013, 'Suffering the impact: psychosis and the professional caregiver', in A Gumley, A Gillham, K Taylor \& M Schwannauer (eds.), Psychosis and Emotion. Routledge, Hove, UK, pp. 23-40.

Husserl, E 1962, Ideas: General introduction to pure phenomenology, trans. WRB Gibson, Collier Books, New York, NY.

Husserl, E 1970, The crisis of European sciences and transcendental phenomenology, trans. D. Carr, Northwestern University Press, Evanston, IL.

Hutchins, J, Rhodes, J, \& Keville, S 2016, 'Emotional earthquakes in the landscape of psychosis: an interpretative phenomenology', The Cognitive Behaviour Therapist, vol. 9. https://doi.org/10.1017/S1754470X16000167

Jacob, KS 2015, 'Recovery model of mental illness: A complementary approach to psychiatric care', Indian journal of psychological medicine, vol. 37, no. 2, p.117, doi: 10.4103/0253-7176.155605.

Janoff-Bulman, R 2010, Shattered assumptions, Simon and Schuster, New York, NY.

Jaspers, K 1963, General Psychopathology, trans. J Hoenig \& M Hamilton, University of Chicago Press, Chicago, IL.

Jones, K 2006, 'A biographic researcher in pursuit of an aesthetic: The use of arts-based (re) presentations in "performative" dissemination of life stories', Qualitative Sociology Review, vol. 2, no. 1, pp.66-85. 
Josselson, R 2017, 'Editor's introduction', Qualitative Psychology, vol. 4, no. 2, p. 119. http://dx.doi.org/10.1037/qup0000104

Kapusta, A 2014, 'Karl Jaspers' Psychopathology and contemporary psychiatry', Postepy $\begin{array}{llll}\text { Psychiatrii } i \text { Neurologii, } & \text { vol. 23, pp. }\end{array}$ https://doi.org/10.1016/j.pin.2014.11.001

Kilcommons, AM \& Morrison, AP 2005, 'Relationships between trauma and psychosis: an exploration of cognitive and dissociative factors', Acta Psychiatrica Scandinavica, vol. 112, no. 5, pp. 351-359. http://dx.doi.org/10.1111/j.1600-0447.2005.00623.x

Kirova, A \& Emme, M 2006, 'Using photography as a means of phenomenological seeing: "Doing Phenomenology" with immigrant children', Indo-Pacific Journal of Phenomenology, vol. 6, no. 1, pp. 1-12. https://doi.org/10.1080/20797222.2006.11433934

Kiser, S. 2004, 'An existential case study of madness: Encounters with divine affliction', Journal of Humanistic Psychology, vol. 44, no. 4, pp.431-454. https://doi.org/10.1177/0022167804269043

Lakoff, G \& Johnson, M 2003, Metaphors we live by. University of Chicago Press, Chicago, IL.

Laing, R 2010, The divided self: An existential study in sanity and madness, Penguin UK, London, UK.

Langdridge, D 2007, Phenomenological psychology: Theory, research and method, Pearson Education, Harlow, UK.

Larkin, M \& Thompson, AR 2012, 'Interpretative phenomenological analysis', in A Thompson \& D Harper (eds), Qualitative research methods in mental health and psychotherapy: a guide for students and practitioners, John Wiley \& Sons, Oxford, UK, pp. 99-116. 
Livingstone, K, Harper, S \& Gillanders, D 2009, 'An exploration of emotion regulation in psychosis', Clinical Psychology \& Psychotherapy: An International Journal of Theory \& Practice, vol. 16, no. 5, pp.418-430. https://doi.org/10.1002/cpp.635

Luderowski, A \& Boden, ZVR 2019, 'Love and incomprehensibility: The hermeneutic labour of caring for and understanding a loved one with psychosis', Health, https://doi.org/10.1177\%2F1363459319829189

Lynch, K 2000, 'The long road back', Journal of clinical psychology, vol. 56, no. 11, pp.14271432. https://doi.org/10.1002/1097-4679(200011)56:11\%3C1427::AIDJCLP5\%3E3.0.CO;2-7

Malla, A, Bechard-Evans, L, Joober, R, King, S \& Abadi, S 2006, 'Understanding the complexities of delay in treatment of psychosis and relevance for early detection interventions', Schizophrenia Research, vol. 86, p.40. https://doi.org/10.1016/S09209964(06)70120-7

McGrath, L \& Reavey, P 2015, 'Seeking fluid possibility and solid ground: Space and movement in mental health service users ' experiences of "crisis"', Social Science and Medicine, vol. 128, pp. 115-117. http://dx.doi.org/10.1016/j.socscimed.2015.01.017

Melle, I \& Barrett, EA 2012, 'Insight and suicidal behavior in first-episode schizophrenia', Expert review of neurotherapeutics, vol. 12, no.3, pp.353-359. https://doi.org/10.1586/ern.11.191

Merleau-Ponty, M 1962, Phenomenology of perception, trans. C. Smith, Routledge, London, UK.

Mind 2011, Listening to experience. An independent inquiry into acute and crisis mental healthcare, $\quad$ viewed 20 December 2018, https://www.mind.org.uk/media/211306/listening_to_experience_web.pdf 
Mishara, AL 2009, 'Klaus Conrad (1905-1961): delusional mood, psychosis, and beginning schizophrenia', Schizophrenia Bulletin, vol. 36, no.1, pp.9-13. https://doi.org/10.1093/schbul/sbp144

Moncrieff, J 2013, The bitterest pills: The troubling story of antipsychotic drugs, Palgrave Macmillan, Houndmills, Basingstoke, Hampshire, UK.

Moran, D \& Mooney, T 2002, The phenomenology reader, Routledge, London, UK.

Morgan, C, Kirkbride, J, Mallett, R, Hutchinson, G, Fearon, P, Morgan, K, Dazzan, P, Craig, T, Harrison, G, Jones, P, Murray, R \& Leff, J 2005, 'Social isolation, ethnicity, and psychosis: Findings from the AESOP first onset psychosis study' Schizophrenia Bulletin, vol. 31, no. 2, pp. 232 - 232.

Morrison, AP, Frame, L \& Larkin, W 2003, 'Relationships between trauma and psychosis: a review and integration', British Journal of Clinical Psychology, vol. 42, no. 4, pp. 331353. http://dx.doi.org/10.1348/014466503322528892

Morrison, AP \& Shiers, D 2014, 'Cognitive behaviour therapy: a rational choice in psychosis', Prescriber, vol. 25, no. 8, pp.6-8. https://doi.org/10.1002/psb.1188

Mueser, K T, Lu, W, Rosenberg, SD \& Wolfe, R 2010, 'The trauma of psychosis: Posttraumatic stress disorder and recent onset psychosis', Schizophrenia research, vol. 116, no. 2, pp. 217-227. https://doi.org/10.1016/j.schres.2009.10.025

Murray, RM 2016, 'Mistakes I have made in my research career', Schizophrenia bulletin, vol. 43, no. 2, pp. 253-256. https://doi.org/10.1093/schbul/sbw165

Muskett, C 2013, 'Trauma-informed care in inpatient mental health settings: A review of the literature', International journal of mental health nursing, vol. 23, no. 1, pp. 51-59. https://doi.org/10.1111/inm.12012 
National Institute for Health and Care Excellence 2014, Psychosis and schizophrenia in adults: prevention and management (CG 178), viewed 1 October 2018, https://www.nice.org.uk/terms-and-conditions\#notice-of- rights)

National Institute of Mental Health 2016, Schizophrenia, viewed 1 October 2018, https://www.nimh.nih.gov/health/topics/schizophrenia/index.shtml

Nelson, B, Parnas, J \& Sass, LA 2014, 'Disturbance of minimal self (ipseity) in schizophrenia: clarification and current status', Schizophr Bull, vol. 40, no. 3, pp. 479-482, doi: 10.1093/schbul/sbu034.

Palumbo, C, Volpe, U, Matanov, A, Priebe, S \& Giacco, D 2015, 'Social networks of patients with psychosis: a systematic review', BMC research notes, vol. 8, no. 1, p.560. https://doi.org/10.1186/s13104-015-1528-7

Parnas, J \& Handest, P 2003, 'Phenomenology of anomalous self-experience in early schizophrenia', Comprehensive psychiatry, vol. 44, no. 2, pp.121-134. https://doi.org/10.1053/comp.2003.50017

Parnas, J, Møller, P, Kircher, T, Thalbitzer, J, Jansson, L, Handest, P \& Zahavi, D 2005, 'EASE: examination of anomalous self-experience', Psychopathology, vol. 38, no. 5, pp.236258. https://doi.org/10.1159/000088441

Pathak, V, Jena, B \& Kalra, S 2013, 'Qualitative research', Perspectives in clinical research, vol. 4, no. 3, p. 192. http://dx.doi.org/10.4103\%2F2229-3485.115389

Peat, G, Rodriguez, A \& Smith, J 2019, 'Interpretive phenomenological analysis applied to healthcare research', Evidence-Based Nursing, vol. 22, no. 1, pp. 7-9. https://doi.org/10.1002/1097-4679(200011)56:11\%3C1427::AID-JCLP5\%3E3.0.CO;2-7 
Pompili, M, Rihmer, Z, Akiskal, HS, Innamorati, M, Iliceto, P, Akiskal, KK, Lester, D, Narciso, V, Ferracuti, S, Tatarelli, R \& De Pisa, E 2008, 'Temperament and personality dimensions in suicidal and nonsuicidal psychiatric inpatients', Psychopathology, vol. 41, no. 5, pp.313-321. https://doi.org/10.1159/000146069

Preti, A \& Cella, M 2010, 'Paranoid thinking as a heuristic', Early Intervention in Psychiatry, vol. 4, no.3, pp.263-266. https://doi.org/10.1111/j.1751-7893.2010.00190.x

Radden, J 2011, On Delusion, Routledge, London, UK.

Ratcliffe, M 2008, Feelings of being: Phenomenology, psychiatry and the sense of reality, Oxford University Press, Oxford, UK.

Ratcliffe 2013, 'Delusional atmosphere and the sense of unreality', in G Stanghellini \& T Fuchs (eds.), One Century of Karl Jaspers' General Psychopathology, Oxford University Press, Oxford, pp. 229-245.

Ratcliffe, M 2017, Real Hallucinations: Psychiatric Illness, Intentionality, and the Interpersonal World, MIT Press, Cambridge, MA.

Ratcliffe, M, Ruddell, M \& Smith, B 2014, 'What is a "sense of foreshortened future?" A phenomenological study of trauma, trust, and time', Frontiers in psychology, vol. 5, pp. 1-11, doi: 10.3389/fpsyg.2014.01026.

Read, J \& Dillon, J 2013, Models of madness: Psychological, social and biological approaches to psychosis, Routledge, Hove, UK.

Read, J, van Os, JV, Morrison, AP \& Ross, CA 2005, 'Childhood trauma, psychosis and schizophrenia: a literature review with theoretical and clinical implications', Acta Psychiatrica Scandinavica, vol. 112, no. 5, pp. 330-350. http://dx.doi.org/10.1111/j.1600-0447.2005.00634.x 
Reavey, P 2012, 'The return to experience: psychology and the visual', in P Reavey (ed.), Visual methods in psychology: Using and interpreting images in qualitative research, Routledge, London, UK, pp. 1-15.

Reavey, P \& Johnson, K 2017, 'Social Representations', in C Willig \& WS Rogers (eds.), The SAGE handbook of qualitative research in psychology, Sage, London, UK, pp.296-315.

Reddy, WM 2001, The navigation of feeling: A framework for the history of emotions, Cambridge University Press, Cambridge, UK.

Reininghaus, UA, Morgan, C, Simpson, J, Dazzan, P, Morgan, K, Doody, GA, Bhugra, D, Leff, P, Jones, R, Murray, P, Fearon, T \& Craig, TKJ, 2008, 'Unemployment, social isolation, achievement-expectation mismatch and psychosis: findings from the AESOP Study', Social Psychiatry and Psychiatric Epidemiology, vol. 43, no. 9, pp. 743-751. http://doi.org/10.1007/s00127-008-0359-4

Reis, HT \& Gable, SL 2003, 'Toward a positive psychology of relationships', in CLM Keyes \& J Haidt (eds.), Flourishing: Positive psychology and the life well-lived, American Psychological Association, Washington, DC, pp. 129-159.

Rhodes, J \& Jakes, S 2004, 'Evidence given for delusions during cognitive behaviour therapy', Clinical Psychology and Psychotherapy, vol. 11, pp. 207-18. https://doi.org/10.1002/cpp.417

Rhodes, J \& Jakes, S 2009, Narrative CBT for psychosis, Hove: Routledge.

Rhodes, J \& Jakes, S 2010, 'Perspectives on the onset of delusions', Clinical Psychology and Psychotherapy, vol. 17, no. 2, pp. 136-146. https://doi.org/10.1002/cpp.675

Robinson, J, Harris, MG, Harrigan, SM, Henry, LP, Farrelly, S, Prosser, A, Schwartz, O, Jackson, H \& McGorry, PD 2010, 'Suicide attempt in first-episode psychosis: a 7.4 year follow- 
up study', Schizophrenia Research, vol. 116, no. 1, pp. 1-8. https://doi.org/10.1016/j.schres.2009.10.009

Rodriguez, A \& Smith, J 2018, 'Phenomenology as a healthcare research method', EvidenceBased Nursing, vol. 21, no. 4, pp. 96-98. https://doi.org/10.1136/eb-2018-102990

Romme, M, Escher, S, Dillon, J, Corstens, D \& Morris, M 2009, Living with voices: 50 stories of recovery, PCCS Books Ltd, Herefordshire, UK.

Sass, LA \& Parnas, J 2003, 'Schizophrenia, consciousness, and the self', Schizophrenia bulletin, vol. 29, no. $3, \quad$ pp.427-444. https://doi.org/10.1093/oxfordjournals.schbul.a007017

Sass, LA \& Pienkos, E 2013, 'Delusion: The Phenomenological Approach', in KWM Fulford, M Davies, R Gipps, G Graham, J Sadler, G Stanghellini \& T Thornton (eds.), The Oxford Handbook of Philosophy and Psychiatry, Oxford University Press, Oxford, UK, pp.632658.

Schwannauer, M 2013, 'Attachment, metallisation and reflective functioning in psychosis', in A Gumley, A Gillham, K Taylor \& M Schwannauer (eds.), Psychosis and Emotion, Routledge, Hove, UK, pp. 68-84.

Seedat, S, Stein, MB, Oosthuizen, PP, Emsley, RA \& Stein, DJ 2003, 'Linking posttraumatic stress disorder and psychosis. A look at epidemiology, phenomenology and treatment', Journal of Nervous and Mental Disease, vol. 191, no. 10, pp. 675-681, doi: 10.1097/01.nmd.0000092177.97317.26.

Seikkula, J 2003, 'Open dialogue integrates individual and systemic approaches in serious psychiatric illness', Smith College Studies in Social Work, vol. 73, no. 2, pp. 227-245. https://doi.org/10.1080/00377310309517683 
Seikkula, J, Aaltonen, J, Alakare, B, Haarakangas, K, Keränen, J \& Lehtinen, K 2006, 'Five-year experience of first-episode nonaffective psychosis in open-dialogue approach: Treatment principles, follow-up outcomes, and two case studies', Psychotherapy research, vol. 16, no. 2, pp. 214-228. https://doi.org/10.1080/10503300500268490

Shaw, R 2010, 'Embedding reflexivity within experiential qualitative psychology', Qualitative research in psychology, vol. 7, no.3, pp. 233-243. http://dx.doi.org/10.1080/14780880802699092

Sin, J, Moone, N \& Wellman, N 2005, 'Developing services for the carers of young adults with early-onset psychosis-listening to their experiences and needs', Journal of psychiatric and mental health nursing, vol. 12, no. 5, pp.589-597. https://doi.org/10.1111/j.1365-2850.2005.00883.x

Slade, M \& Longden, E 2015, 'Empirical evidence about recovery and mental health', BMC psychiatry, vol. 15, no. 1, p.285. https://doi.org/10.1186/s12888-015-0678-4

Smith, JA 2011, 'Evaluating the contribution of interpretative phenomenological analysis', Health psychology review, vol. 5, no. 1, pp. 9-27. https://doi.org/10.1080/17437199.2010.510659

Smith, JA, Flowers, P \& Larkin, M 2009, Interpretative Phenomenological Analysis: Theory, Method and Research, Sage, London, UK.

Smith, JA \& Osborn, M 2004, 'Interpretative phenomenological analysis', Doing social psychology research, pp.229-254. https://doi.org/10.1002/9780470776278

Smith, JA \& Osborn, M 2008, 'Interpretative phenomenological analysis', in JA Smith (ed.), Qualitative Psychology: A Practical Guide to Research Methods, Sage, London, UK. 
Smith, JA \& Osborn, M 2015a, 'Interpretative phenomenological analysis as a useful methodology for research on the lived experience of pain', British Journal of Pain, vol. 9, no. 1, pp.41-42, doi: 10.1177/2049463714541642.

Smith, JA \& Osborn, M 2015b, 'Interpretative Phenomenological Analysis', in JA Smith (ed.), Qualitative Psychology - A practical guide to research methods, SAGE, London, UK, pp 25-53.

Sündermann, O, Onwumere, J, Kane, F, Morgan, C \& Kuipers, E 2014, 'Social networks and support in first-episode psychosis: Exploring the role of loneliness and anxiety', Social Psychiatry and Psychiatric Epidemiology, vol. 49, no. 3, pp. 359-366. https://doi.org/10.1007/s00127-013-0754-3

Tarrier, N 2005, 'Co-morbidity and associated clinical problems in schizophrenia: their nature and implications for comprehensive cognitive-behavioural treatment', Behaviour Change, vol. 22, no. 3, pp. 125-142. https://doi.org/10.1375/bech.2005.22.3.125

Tarrier, N, Khan, S, Cater, J \& Picken, A 2007, 'The subjective consequences of suffering a first episode psychosis: trauma and suicide behaviour', Social Psychiatry and Psychiatric Epidemiology, vol. 42, no. 1, pp.29-35.

The British Psychological Society 2014, Understanding Psychosis and Schizophrenia. Why people sometimes hear voices, believe things that others find strange, or appear out of touch with reality, and what can help, viewed 15 January 2019, http://create.canterbury.ac.uk/16712/1/16712.pdf

Thompson, J 2018, '"Shared intelligibility" and two reflexive strategies as methods of supporting "responsible decisions" in a hermeneutic phenomenological study, International Journal of Social Research Methodology, vol. 21, no. 5, pp. 575-589. https://doi.org/10.1080/13645579.2018.1454641 
Todres, L 2007, Embodied enquiry: phenomenological touchstones for research, psychotherapy and spirituality, Palgrave Macmillan, Basingstoke, UK.

Tuval-Mashiach, R 2017, 'Raising the curtain: The importance of transparency in qualitative research', Qualitative Psychology, vol. 4, no. 2, p.126. http://dx.doi.org/10.1037/qup0000062

Van Harmelen, AL, Kievit, RA, loannidis, K, Neufeld, S, Jones, PB, Bullmore, E, Dolan, R, Fonagy, P, Goodyer, I \& NSPN Consortium 2017, 'Adolescent friendships predict later resilient functioning across psychosocial domains in a healthy community cohort', Psychological medicine, vol. 47, no. 13, pp.2312-2322. https://doi.org/10.1017/S0033291717000836

Van Os, J, Linscott, RJ, Myin-Germeys, I, Delespaul, P \& Krabbendam, L 2009, 'A systematic review and meta-analysis of the psychosis continuum: evidence for a psychosis proneness-persistence-impairment model of psychotic disorder', Psychological medicine, vol. 39, no. 2, pp. 179-195. https://doi.org/10.1017/S0033291708003814

Wallcraft, J. \& Michaelson, J. 2013, 'Developing a survivor discourse to replace the psychopathology of breakdown and crisis', in G Newnes, C Holmes \& C Dunn (eds.), This is Madness Too, Critical Persepctives on Mental Health Issues, PCCS Books, Rosson-Wye.

Warnock, M 1987, Memory, Faber, London, UK.

Willig, C 2013, Introducing qualitative research in psychology, 3rd edn, Open University Press, Maidenhead, Berkshire.

Windell, D, Norman, R \& Malla, AK 2012, 'The personal meaning of recovery among individuals treated for a first episode of psychosis', Psychiatric Services, vol. 63, no. 6, pp.548-553. https://doi.org/10.1176/appi.ps.201100424 
Yung, AR, Buckby, JA, Cotton, SM, Cosgrave, EM, Killackey, EJ, Stanford, C, Godfrey, K \& McGorry, PD 2006, 'Psychotic-like experiences in non-psychotic help-seekers: associations with distress, depression, and disability', Schizophrenia Bulletin, vol. 32, no. 2, pp. 352-359. http://dx.doi.org/10.1093/schbul/sbj018

Zahavi, D 2001, 'Beyond empathy. Phenomenological approaches to intersubjectivity', Journal of consciousness studies, vol. 8, no. 5-7, pp.151-167.

Zeedyk, MS 2006, 'From intersubjectivity to subjectivity: The transformative roles of emotional intimacy and imitation. Infant and Child Development', An International Journal of Research and Practice, vol. 15, no. 3, pp.321-344. https://doi.org/10.1002/icd.45 